\title{
In vitro and in vivo antitumor effects of the Egyptian scorpion Androctonus amoreuxi venom in an Ehrlich ascites tumor model
}

\author{
Mohamed L. Salem', Nahla M. Shoukry², Wafaa K. Teleb², Mohamed M. Abdel-Daim³ \\ and Mohamed A. Abdel-Rahman ${ }^{*}$
}

\begin{abstract}
Scorpion venom is a highly complex mixture of about 100-700 different components, where peptides are the major constituents with various biological and pharmacological properties including anticancer activities. In this study, anticancer efficacy of the venom of the Egyptian scorpion Androctonus amoreuxi has been evaluated. In vitro, the human breast cancer MCF-7 cell line was treated with the venom and the $I_{50}$ was estimated. In vivo studies, Ehrlich ascites carcinoma (EAC) cells were inoculated into CD-1 mice intraperitoneally to form liquid tumor or subcutaneously to form solid tumor and then treated with intraperitoneal injection with venom $(0.22 \mathrm{mg} / \mathrm{kg})$ every other day. The total tumor cells in the ascitic fluid and the size of the solid tumor were assessed after 14 and 30 days, respectively. In addition, the mean survival time (MST), body weight, tumor volume, PCV, viability of tumor cells, CBC, AST, ALP, creatinine, oxidative stress biomarkers (GSH, MDA, PCC), tumor marker Ki67, growth factor VEGF and caspase-3 were measured in normal control, EAC control and venom-treated groups $(n=6)$. Treatment with venom induced anti-tumor effects against liquid and in solid tumors as indicated by a significant $(P<0.05)$ reduction in tumor volume/size, count of viable EAC cells, expression of Ki67 and VEGF as well as by remarkable increases in MST and caspase-3 expression as compared to non-treated group. Interestingly, the venom restored the altered hematological and biochemical parameters of tumor-bearing animals and significantly increased their life span. These data indicate to (1) the cytotoxic potential effects of A. amoreuxi on tumor cells via anti-proliferative, apoptotic and anti-angiogenic activities; (2) opening a new avenue for further studies on the anti-cancer effects of this agent.
\end{abstract}

Keywords: Androctonus amoreuxi, Apoptosis, Cancer, Egypt, Scorpion, Venom, Ehrlich ascites carcinoma

\section{Background}

According to the reports and statistics from the International Agency for Research on Cancer (IARC) and the World Health Organization (WHO), cancer has become the leading cause of deaths worldwide (7.6, 8.2 million deaths in 2008 and 2012, respectively) (Jemal et al. 2011; Ferlay et al. 2013). However chemotherapy and radiotherapy are extensively being used to treat several types of tumors, they have many disadvantages such as (1) deleterious side effects on normal cells (lack of specificity); (2)

\footnotetext{
*Correspondence: mohamed_hassanain@science.suez.edu.eg

${ }^{4}$ Zoology Department, Faculty of Science, Suez Canal University, Ismailia 41522, Egypt

Full list of author information is available at the end of the article
}

low success rate and (3) high risk of recurrence. Consequently, development of new safe and effective strategies for cancer diagnosis and treatment is extremely needed. One of these alternative approaches is using anticancer peptides derived from animal venoms including scorpions. Various previous studies revealed effectiveness of the crude scorpion venoms and certain purified peptides (such as iberiotoxin margatoxin, charybdotoxin, AGAPSYPU2 and chlorotoxin) against cancer cells through different mechanism of actions (Deshane et al. 2003; Bloch et al. 2007; Liu et al. 2009; Jang et al. 2011; Zhao et al. 2011; Shao et al. 2014; Ding et al. 2014; Ortiz et al. 2015).

Scorpion venom is a cocktail of protein (enzymes and peptides) and non-protein (inorganic salts, lipids, nucleotides, free amino acids and water) substances produced 
by the venom gland for defense and prey capture (Rodriguez de la Vega and Possani 2005; Abdel-Rahman et al. 2015). Disulfide-bridged peptides and non-disulfidebridged peptides constitute the major groups of scorpion venom and many of them have been characterized with analgesic, anti-epileptic, hemolytic, anti-thrombotic, anti-inflammatory, antimicrobial and anticancer activities (Yu et al. 1992; Wang et al. 2001; Zeng et al. 2005; Song et al. 2005; Shao et al. 2007; Mamelak 2011; Harrison et al. 2014, 2016; Almaaytah and Albalas 2014; Abdel-Rahman et al. 2016).

The anticancer efficacy of scorpion venoms has been examined in various types of cancers as glioma, neuroblastoma, leukemia, lymphoma, breast, lung, prostate and pancreatic cancer (Ding et al. 2014). Only a few toxins have been found to be the responsible for these anticancer effects and exert their action by three different mechanisms: (1) blocking specific ion channels (Jager et al. 2004); (2) inhibiting invasion and metastasis of cancer cells (Deshane et al. 2003); (3) activating intracellular pathways leading to cell cycle arrest and apoptosis (Gupta et al. 2010). Recently, venom from the Buthidae scorpions Androctonus bicolor, Androctonus crassicauda, and Leiurus quinquestriatus (collected from Saudi Arabia) revealed strong anticancer activity on colorectal and breast cancer cell lines (HCT-116 and MDA-MB-231, respectively) through decreasing cell motility and colony formation of cancer cells (Al-Asmari et al. 2016).

However several scorpion species (about 24 species) are widespread in Egypt, only few studies highlighted anticancer activity of scorpion venoms such as $L$. quinquestriatus (Omran 2003). The present study was conducted to examine the cytotoxic activity and mechanism of action of the Egyptian scorpion venom $A$. amoreuxi on the Ehrlich ascites carcinoma (EAC) cells and human breast cancer MCF-7 cell line using both in vitro and in vivo approaches.

\section{Methods}

\section{Scorpion venom collection and preparation}

About 200 specimens of $A$. amoreuxi scorpions were captured from the Western Mediterranean Costal Desert (Alexandria, Egypt) in August 2010. Scorpions were kept alive in separate plastic containers and fed with cockroaches and received water ad libitum. The crude venom was collected using electrical stimulation (12-16 V, $3 \mathrm{~ms})$ of the scorpion telson according to the method described by Abdel-Rahman et al. (2013). The pooled venom (collected from different scorpion specimens) was dissolved in distilled water and centrifuged for $10 \mathrm{~min}$ at $5000 \mathrm{rpm}$ to remove cellular debris. Then, supernatant was immediately freeze dried (Labconco freeze dry system, model 77500 , USA) and stored at $-20^{\circ} \mathrm{C}$ until use.
Experimental animals, ethics and cancer cell lines

Swiss Webster albino mice (20-25 g) were housed in plastic cages (ten animals/cage) under standard laboratory conditions $\left(27 \pm 2{ }^{\circ} \mathrm{C} ; 70-80 \%\right.$ humidity; 12 -h light/darkness cycle) with standard pellet diet and water ad libitum. The animals were handled in accordance with current guidelines for the care of laboratory animals and ethical guidelines for the investigation of experimental pain in conscious animals. All efforts were made to minimize the number of animals used and their suffering. The first inoculum of EAC and MCF-7 cell lines was purchased from the National Cancer Institute, and VACSERA (Cairo, Egypt), respectively. EAC cells were propagated in the peritoneal cavity of mice through serial intraperitoneal (IP) transplantation of $10^{6}$ cells (in $0.2 \mathrm{ml}$ of PBS/animal) and transferred every 7 days to new animals. Mice were monitored daily and cell viability was evaluated using trypan blue dye exclusion method (Bincoletto et al. 2005).

\section{Determination of $\mathrm{LD}_{50}$}

The approximate median lethal dose $\left(\mathrm{LD}_{50}\right)$ of $A$. amoreuxi venom was estimated using a limited number of experimental animals. Briefly, eight weighted mice were treated with IP injection with different doses (D) of scorpion venom. Then, the animals were monitored for $24 \mathrm{~h}$ and the survival time $(\mathrm{T})$ was recorded in each case. The regression line was generated using the data of $\mathrm{D} / \mathrm{T}$ versus $\mathrm{D}$ and $\mathrm{LD}_{50}$ was calculated following the equations described in Meier and Theakston (1986). The approximate $\mathrm{LD}_{50}$ of $A$. amoreuxi venom was calculated to be $1.1 \mathrm{mg} / \mathrm{kg}$.

\section{In vitro experiments Cell survival assay}

The in vitro cytotoxic effect of scorpion venom was conducted using MCF-7 cell line. Cell survival was determined using sulphorhodamine B (SRB, Biotium, USA) method as previously described (Skehan et al. 1990). Cells were seeded in 96 well microtiter plates at a concentration of 1000-2000 cells/well, $100 \mu \mathrm{l} /$ well. After $24 \mathrm{~h}$, cells were incubated for 24,48 and $72 \mathrm{~h}$ with various concentrations of $A$. amoreuxi venom $(0,0.01,0.1,1,10$, $100 \mu \mathrm{g} / \mathrm{ml})$. After $72 \mathrm{~h}$ from venom application, cells were fixed with $10 \%$ trichloroacetic acid $(150 \mu \mathrm{l} /$ well for $1 \mathrm{~h}$ at $4{ }^{\circ} \mathrm{C}$ ). Cells washed three times using water and stained for 10-30 min at room temperature with $0.4 \%$ SRB dissolved in $1 \%$ acetic acid $(70 \mu \mathrm{l} /$ well). The unbounded dye was removed with $1 \%$ acetic acid. The plates were air dried for $24 \mathrm{~h}$, the dye was solubilized with $10 \mathrm{mM}$ tris base of ( $\mathrm{pH} 7.4,150 \mu \mathrm{l} /$ well) for $5 \mathrm{~min}$ on a shaker at $1600 \mathrm{rpm}$. The optical density (OD) was measured spectrophotometrically at $540 \mathrm{~nm}$ using the Bio-Rad ELISA 
microplate reader (Model 550, Japan). The value of $\mathrm{IC}_{50}$ was calculated using sigmoidal concentration response curve fitting models (Sigma plot software).

\section{DNA extraction and fragmentation analysis}

DNA was extracted from both control and treated MCF-7 cells and fragmentation assay was performed (Giri et al. 2003, Peitsch et al. 1993). Cells were lysed using $10 \%$ sodium dodecyl sulfate (SDS) for $30 \mathrm{~min}$. Potassium acetate $(8 \mathrm{M})$ was added to the supernatant and incubated for $1 \mathrm{~h}$ at $4{ }^{\circ} \mathrm{C}$. After spinning at $7000 \mathrm{rpm}$, an equal volume of distilled phenol, chloroform and isoamyl alcohol (25:24:1) mixture was added. The mixture was subjected to centrifugation for $30 \mathrm{~min}$ at $3000 \mathrm{rpm}$, $20 \mu \mathrm{l} / \mathrm{ml}$ of RNase was added and incubated for $30 \mathrm{~min}$ at $37{ }^{\circ} \mathrm{C}$. Two volumes of chilled ethanol was added and allowed to stand at $20{ }^{\circ} \mathrm{C}$ overnight. The solution was centrifuged $\left(10,000 \mathrm{rpm}\right.$ for $1 \mathrm{~h}$ at $\left.4{ }^{\circ} \mathrm{C}\right)$ and the pellet obtained was dissolved in Tris-EDTA (TE) buffer. DNA was estimated by recording the absorbance at $260 \mathrm{~nm}$ and $280 \mathrm{~nm}$. DNA was electrophoresed on $2 \%$ agarose gel at $50 \mathrm{~V}$ using Tris-borate-EDTA (TBE) buffer. DNA was visualized by incorporation of ethidium bromide $(1 \mathrm{mg} / \mathrm{ml})$ in the gel during casting and viewed under UV illumination (302 nm). Documentation was done using BIO-DOC IT $^{\mathrm{TM}}$ system.

\section{In vivo experiments}

\section{Ehrlich ascites carcinoma model and animal groups}

In order to examine in vivo anticancer efficacy of scorpion venom, 80 female albino mice were inoculated with i.p. injection of $10^{6} \mathrm{EAC}$ cells in a volume of $0.2 \mathrm{ml}$. These mice were randomly divided into five groups (10 or 20 mice/group). After $48 \mathrm{~h}$ of tumor inoculation, mice were treated i.p. with $A$. amoreuxi venom or cisplatin every other day according to the following scheme: Group I: normal mice saline-control group (normal control): ten normal mice were injected i.p. with $0.2 \mathrm{ml}$ physiological saline $(0.9 \mathrm{~g} / \mathrm{dL})$ every other day for 13 days. Group II: EAC-bearing mice control group (EAC control): 20 EAC-bearing mice injected with $0.2 \mathrm{ml}$ physiological saline every other day for 13 days. Group III: EAC-bearing mice venom-treated group: 20 EAC-bearing mice treated with $A$. amoreuxi venom $\left(1 / 5 \mathrm{LD}_{50} ; 0.22 \mathrm{mg} / \mathrm{kg}\right)$ every other day for 13 days. Group IV: EAC-bearing mice cisplatin-treated group (positive control): 20 EAC-bearing mice treated with cisplatin $(0.25 \mathrm{mg} / \mathrm{kg}$; Santos et al. 2011) every other day for 13 days. Group V: A. amoreuxi venom-treated group: ten normal mice treated with $1 / 5$ $\mathrm{LD}_{50}(0.22 \mathrm{mg} / \mathrm{kg})$ of $A$. amoreuxi venom every other day for 13 days. The animals with ascitic tumor were weighed every 3 days. Total experimental period was 25 days and at 14th day, 6 mice in each group were anesthetized and sacrificed to (1) evaluate anti-tumor activity of scorpion venom and (2) to conduct hematological, biochemi$\mathrm{cal}$ and histopathological assay. The remaining mice in Group II-Group IV ( $\mathrm{n}=14$ mice/each group) were kept alive to estimate the mean survival time (MST) and percent increase in life span (\% ILS).

Collection of ascitic fluid The ascitic fluid from control and treated groups was collected for the immediate determination of (1) ascites tumor volume; (2) packed cell volume (PCV) and (3) total count/viability of Ehrlich ascites tumor cells (EAT) using hemocytometer and dyeexclusion technique, respectively (Nicol and Prasad 2006). Viability percentage of EAT cells was calculated according to the following equation: (No. of viable/No. of viable and dead cells) $\times 100$.

Calculation of MST and percentage of ILS, T/C and TIR MST of each group was monitored by recording the mortality daily. The end point of experiment was determined by the spontaneous death of animals and MST was calculated according to the equation: $\mathrm{MST}=$ (day of first death + day of last death)/2. The percentage of ILS was calculated using equation of Nicol and Prasad (2006) $(\mathrm{ILS} \%=(\mathrm{T}-\mathrm{C}) / \mathrm{C} \times 100)$, where $\mathrm{T}$ represents MST of treated animals and C represents MST of the control group. T/C\% (treated vs. EAC control) was calculated as MST of treated animals/MST of control group. TIR\% (tumor-growth inhibition rate $)=(C-T) / C \times 100$, where $\mathrm{T}$ represents mean tumor volume of treated group and $\mathrm{C}$ represents mean tumor volume of the control group. According to the criteria of National Cancer Institute (NCI), T/C exceeding $125 \%$ and ILS exceeding $25 \%$ indicate that the drug has a significant anti-tumor activity (Plowman et al. 1997).

Hematological and biochemical assays Blood was withdrawn on day 14 by cardiac puncture method from all animal groups in tubes containing EDTA (for hematological assays) and without anticoagulant (for serum biochemical analysis) in accordance with the method of Frankenberg (1979). Hemoglobin (Hb) and count of white blood cells (WBCs), red blood cells (RBCs) and differential leukocyte were analyzed using standard automated procedures. Biochemical parameters of creatinine, aspartate aminotransferase (AST) and alkaline phosphatase (ALP) were measured in serum using commercial kits (Biodiagnostic Company for Laboratory Services). The levels of liver (see "Tissue collection and histopathological examination" section) glutathione (GSH, non-enzymatic antioxidant), malondialdehyde (MDA, end product of lipid peroxidation) and protein carbonyl content (PCC, a marker of protein oxidation) were determined according to Beutler 
et al. (1963), Ohkawa et al. (1979) and Levine et al. (1994), respectively.

Tissue collection and histopathological examination Liver and kidney were immediately excised after animal decapitation and rinsed in saline. Small portions from liver and kidney were preserved in $10 \%$ neutral buffered formalin for histopathological examinations according to Bancroft et al. (1996). Hematoxylin and eosin (H\&E) stained sections were examined by a light microscope and photographed. The rest of liver tissues were homogenized for biochemical analysis.

\section{Ehrlich solid tumor model}

Forty female albino mice were randomly divided into four groups (ten mice/group), Group I was kept as control while solid tumor was induced in the other three groups (Group II, III and IV) by subcutaneous (s.c.) inoculation of $0.2 \mathrm{ml}$ of EAT cells $\left(1 \times 10^{6}\right.$ cells/mouse $)$ into the thigh of the lower limb (Mohamed et al. 2003). After 1 week of tumor inoculation, mice were intraperitoneally treated with $A$. amoreuxi venom or cisplatin every other day according to the following scheme. Group II: ten tumorized mice injected with $0.2 \mathrm{ml}$ of PBS every other day for 30 days. Group III: ten tumorized mice treated with $1 / 5 \mathrm{LD}_{50}$ A. amoreuxi venom $(0.22 \mathrm{mg} / \mathrm{kg})$ every other day for 30 days. Group IV: (positive control) ten tumorized mice treated with cisplatin $(0.25 \mathrm{mg} / \mathrm{kg}$, Santos et al. 2011) every other day for 30 days. Tumor mass was measured from the 5th day of tumor inoculation. The measurement was carried out every 5 days for a period of 30 days. The volume of solid tumor was gauged using Vernier caliper (after shaving the tumor bearing thigh of each animal) and was calculated using the formula of $\mathrm{A} \times \mathrm{B}^{2} \times 0.5$, where $\mathrm{A}$ and $\mathrm{B}$ are the longest and the shortest diameter of tumor, respectively (Orsolic et al. 2006). Five mice from each group were sacrificed on day 31 and tumor mass was removed, weighed, tabulated and preserved in buffered formalin and processed for immunohistochemical (IHC) investigations of the tumor markers KI67, caspase3 and VEGF (markers of proliferation, apoptosis and angiogenesis, respectively).

Immunohistochemical analysis of solid tumors Ehrlich solid tumors were harvested, fixed in formalin and paraffin embedded for IHC analysis (Jakob et al. 2008). After antigen retrieval with $10 \mathrm{mM}$ sodium citrate buffer ( $\mathrm{pH}$ 6.0) at $80^{\circ} \mathrm{C}$ for $10 \mathrm{~min}$, endogenous peroxidases were blocked by $3 \%$ hydrogen peroxide in PBS for $10 \mathrm{~min}$. The slides were then incubated overnight with primary antibodies against Ki67, caspase-3 and VEGF at $4{ }^{\circ} \mathrm{C}$ in a humidified chamber and then incubated with horseradish peroxidase (HRP)-conjugated secondary antibodies at 1:100 dilutions for $30 \mathrm{~min}$ at $37^{\circ} \mathrm{C}$ and visualized by $3,3^{\prime}$-diaminobenzidine tetra hydrochloride reagent (Broad spectrum LABSA Detection System from Invitrogen Cat. No. 95-9943B). The sections were counterstained with hematoxylin and digitally imaged. For IHC quantification, one thousand cells from at least four separate tissue sections were counted (no. of animals per group $=3$ ) using image J software (version 1.48, 32 bit). The number of positive brownstained cells over the total number of cells was estimated and used to determine the percentage (\%) of staining area for each tumor marker.

\section{Statistical analysis}

Statistical analysis of data was evaluated by one-way ANOVA followed by Tukey-Kramer test (for multiple comparison) to compare between control and treated groups. P values $<0.05$ were considered as indicative of significance for all comparisons made. All statistical analyses were performed using Sigmaplot statistical software package version 11 .

\section{Results}

\section{In vitro cytotoxic effect of $A$. amoreuxi venom}

The short-term in vitro cytotoxicity study showed that the $\mathrm{IC}_{50}$ value of $A$. amoreuxi venom on MCF-7 cell line was $0.61 \mu \mathrm{g} / \mathrm{ml}$. In an attempt to check whether the death of MCF-7 cells that occurred as a consequence of $A$. amoreuxi venom treatment was due to apoptosis, DNA fragmentation analysis was performed. DNA was extracted from both control and treated cells after $24 \mathrm{~h}$. The data in Fig. 1 revealed that scorpion venom induced DNA fragmentation when compared to control cells.

\section{Effect of $A$. amoreuxi venom on tumor growth and survival of EAC-bearing mice}

Treatment of EAC-bearing mice with $1 / 5 \mathrm{LD}_{50}$ of $A$. amoreuxi venom $(0.22 \mathrm{mg} / \mathrm{kg})$ significantly reduced $(\mathrm{P}<0.05)$ the increases in the mouse body weight, ascitic volume, $\mathrm{PCV}$, total tumor cell counts and numbers of viable tumor cells in EAC-bearing mice as compared to non-treated animals (Table 1; Fig. 2). These results indicate that $A$. amoreuxi venom possesses significant anti-tumor effects which reached $16.32 \%$. On the other hand, the percentage of non-viable tumor cells (17.5\%), MST (19.5 days), ILS (25.8\%), the percentage of T/C (125.81\%), and tumor growth inhibition (TIR\%, $25.41 \%$ ) of scorpion venom-treated mice were increased as compared to control tumor-bearing mice (Table 1; Fig. 2).

\section{Influence of $A$. amoreuxi venom on hematological and biochemical parameters of EAC-bearing mice}

The data in Tables 2 and 3 showed that treatment with $A$. amoreuxi venom ameliorated EAC-induced alteration 


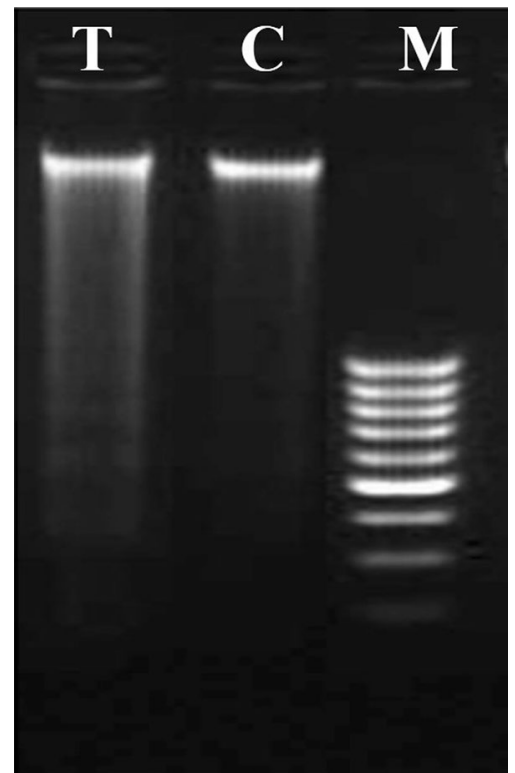

Fig. 1 Genomic DNA fragmentation analysis of MCF-7 cells after treatment with the scorpion venom A. amoreuxi. DNA was resolved on a $2 \%$ agarose gel and visualized with ethidium bromide. Lane $T$ treated cells with $0.5 \mu \mathrm{g} / \mathrm{ml}$ of scorpion venom for $24 \mathrm{~h}$, lane $\mathrm{C}$ untreated cells (control), lane $\mathrm{M}$ molecular weight marker (1 kb ladder)

in hematological and biochemical parameters, including, RBCs and WBCs count, activities of AST and ALP. Treatment with venom significantly decreased the elevated levels of PCC (a biomarker for protein oxidation) and MDA (a biomarker for lipid peroxidation) and restored the level of GSH in EAC-bearing mice. These results were supported by histopathological sections of liver (Fig. 3) and kidney (Fig. 4), where sections of liver and kidney demonstrated a protective effect of $A$. amoreuxi venom to overcome the deleterious changes resulted from tumor development.

\section{Effect of scorpion venom on solid tumor}

In solid tumor, the average tumor volume in mice treated with $A$. amoreuxi venom every other day for 30 days was markedly $(\mathrm{P}<0.05)$ decreased $\left(1.43 \pm 0.07 \mathrm{~mm}^{3}\right)$ when compared to that of control mice $\left(2.67 \pm 0.26 \mathrm{~mm}^{3}\right.$; Fig. 5), reaching about $-46.4 \%$. Quantitatively the weight of tumor lumps extracted from mice treated with scorpion venom was smaller than those of control mice. In order to explore mode of action of $A$. amoreuxi venom on solid tumor, IHC analysis of Ki67, caspase-3 and VEGF expression in Ehrlich solid tumor tissues harvested on day 30 was evaluated. It was found that a significant $(\mathrm{P}<0.05)$ inhibition in KI67 expression was observed in solid tumors from mice treated with $A$. amoreuxi venom as compared to control mice. Also, treatment with $A$. amoreuxi venom significantly enhanced the expression of the apoptotic molecule caspase-3 in tumor tissues. Furthermore, scorpion venom down-regulated the expression of VEGF in tumor tissues, indicating that $A$. amoreuxi venom is able to inhibit process of neovascularization (Fig. 6).

\section{Discussion}

The present study revealed cytotoxic/anti-tumor properties of $A$. amoreuxi on cancer cell lines (MCF-7) and on experimental animal tumor models (Ehrlich ascites and solid tumors). Treatment with $A$. amoreuxi venom showed anti-cancer activity both in vitro or in vivo settings. The toxicity of the venom on cancer cells may be related to its capability to induce necrosis or apoptosis in cancer cells. Several previous studies reported necrotizing and apoptotic effects of scorpion venom peptides on different cancer cell lines. Almaaytah et al. (2012) characterized the cytolytic peptides AamAP1 and AamAP2 (18 amino acids each) from the venom of North African scorpion $A$. amoreuxi. They found that the natural peptides AamAP1 and AamAP2 showed moderate antiproliferative activity against the examined cell lines ( $\mathrm{LNCaP}$, U251, PC3 and HMEC-1). While the synthetic analog AamAP-S1 showed higher anticancer efficacy through inducing necrosis in PC3 prostate cancer cell line. The venom peptide Acra3 (66 amino acids) from the Turkish scorpion $A$. crassicauda induced marked cytotoxic effect $\left(\mathrm{IC}_{50}\right.$ value of $\left.5 \mu \mathrm{g} / \mathrm{ml}\right)$ on mouse brain tumor cells (BC3H1) through both necrotic and apoptotic pathways (Caliskan et al. 2013). Also, previous studies described

Table 1 Effect of $A$. amoreuxi venom on body weight and survival time of EAC-bearing mice

\begin{tabular}{|c|c|c|c|c|c|c|c|}
\hline & \multicolumn{2}{|c|}{ Body weight (g) } & \multirow{2}{*}{$\begin{array}{l}\text { Survival time } \\
\text { range (days) }\end{array}$} & \multirow[t]{2}{*}{ MST (days) } & \multirow[t]{2}{*}{ ILS (\%) } & \multirow[t]{2}{*}{$\mathrm{T} / \mathrm{C}(\%)$} & \multirow[t]{2}{*}{ TIR (\%) } \\
\hline & 1st day & 12th day & & & & & \\
\hline EAC control & $21.20 \pm 2.41$ & $31.62 \pm 3.21$ & $12-19$ & 15.5 & - & - & - \\
\hline $\mathrm{EAC}+1 / 5 \mathrm{LD}_{50}$ A. amoreuxi venom & $20.21 \pm 1.84$ & $28.77 \pm 2.33$ & $16-23$ & 19.5 & $25.80^{*}$ & $125.81^{*}$ & 25.41 \\
\hline EAC + cisplatin $(0.25 \mathrm{mg} / \mathrm{kg})$ & $21.48 \pm 2.19$ & $28.48 \pm 3.76$ & $16-25$ & 20.5 & $32.25^{*}$ & $132.26^{*}$ & 23.88 \\
\hline
\end{tabular}

Data are presented as mean \pm SEM (six animals/group)

* Significant difference between EAC control and treated groups using student unpaired t test $(P<0.05)$ 


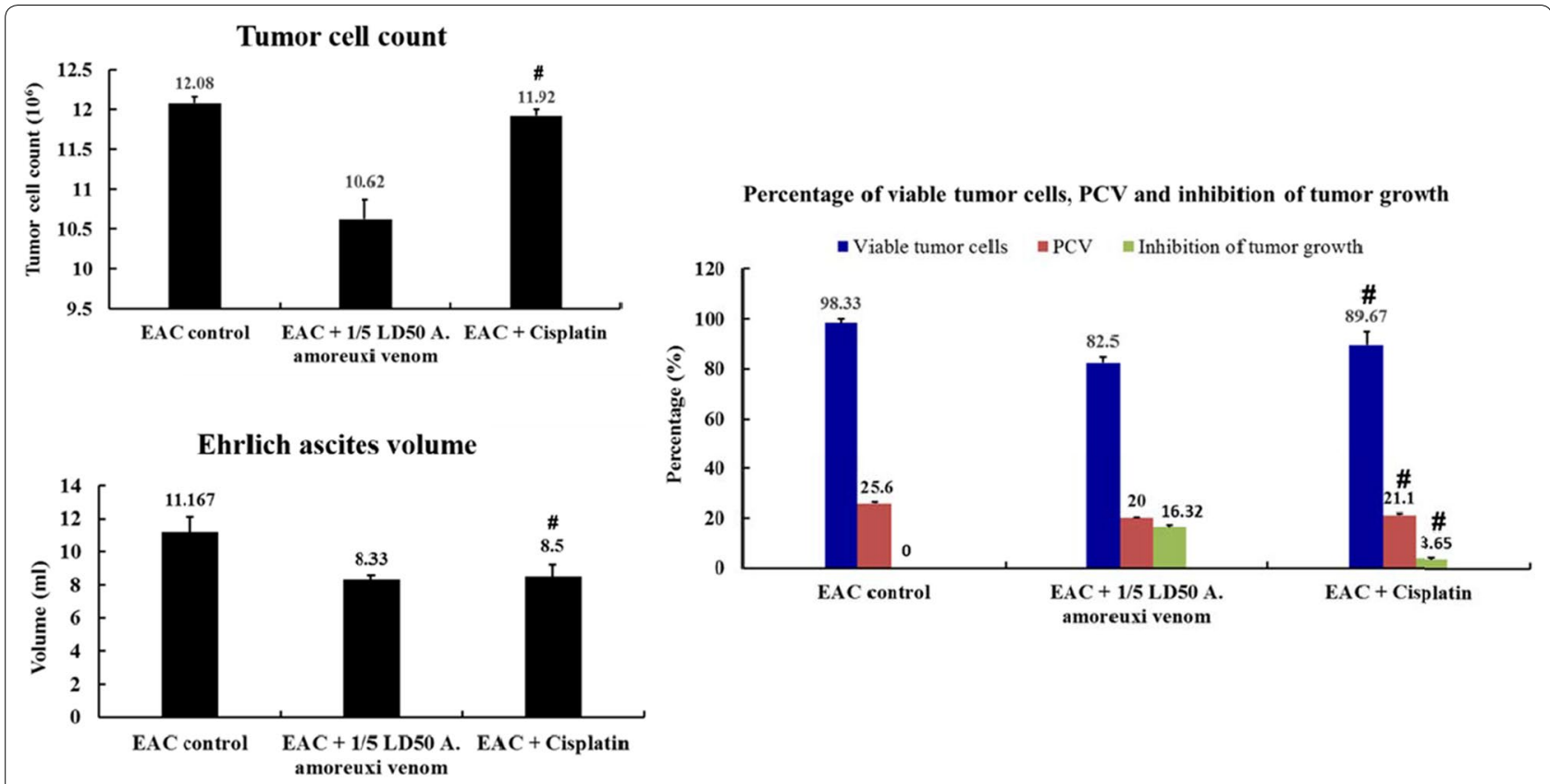

Fig. 2 Effect of A. amoreuxi venom on tumor growth (tumor cell count and viability, ascites volume and PCV) of EAC-bearing mice. Hash symbol represents a significant difference between the three animal groups (EAC control, EAC $+1 / 5 \mathrm{LD}_{50}$ A. amoreuxi venom and EAC + cisplatin) using one-way ANOVA $(P \leq 0.05)$ followed by a Tukey post hoc test for multiple comparisons

Table 2 Effect of $A$. amoreuxi venom on hematological parameters of EAC-bearing mice

\begin{tabular}{|c|c|c|c|c|c|c|}
\hline & $\begin{array}{l}\text { RBCs count } \\
\left(\times 10^{6} / \mu \mathrm{l}\right)\end{array}$ & $\begin{array}{l}\text { Haemoglobin } \\
\text { (\%) (g/dl) }\end{array}$ & $\begin{array}{l}\text { WBCs count } \\
\left(\times 10^{3} / \mu \mathrm{l}\right)\end{array}$ & $\begin{array}{l}\text { Neutrophil } \\
\text { (\%) }\end{array}$ & $\begin{array}{l}\text { Lymphocyte } \\
(\%)\end{array}$ & $\begin{array}{l}\text { Monocyte } \\
\text { (\%) }\end{array}$ \\
\hline Normal control & $4.06 \pm 0.18$ & $6.08 \pm 0.15$ & $2.31 \pm 0.29$ & $45.06 \pm 0.39$ & $50.48 \pm 0.57$ & $3.58 \pm 0.29$ \\
\hline EAC control & $2.44 \pm 0.18$ & $3.83 \pm 0.16$ & $3.23 \pm 0.37$ & $57.43 \pm 0.42$ & $38.53 \pm 0.43$ & $3.31 \pm 0.15$ \\
\hline $\begin{array}{l}\mathrm{EAC}+1 / 5 \mathrm{LD}_{50} A . \\
\text { amoreuxi venom }\end{array}$ & $3.96 \pm 0.0 .8$ & $6.03 \pm 0.12$ & $1.86 \pm 0.23$ & $45.41 \pm 74$ & $50.66 \pm 0.84$ & $3.21 \pm 0.16$ \\
\hline $\begin{array}{c}\text { EAC + cisplatin } \\
(0.25 \mathrm{mg} / \mathrm{kg})\end{array}$ & $3.23 \pm 0.42$ & $5.60 \pm 0.62$ & $3.11 \pm 0.10$ & $60.73 \pm 3.14$ & $38.75 \pm 2.65$ & $3.50 \pm 0.18$ \\
\hline $\begin{array}{l}1 / 5 \mathrm{LD}_{50} \text { A. amoreuxi } \\
\text { venom }\end{array}$ & $4.59 \pm 0.08^{\#}$ & $6.38 \pm 0.32^{\#}$ & $2.71 \pm 0.26^{\#}$ & $44.23 \pm 1.73^{\#}$ & $51.55 \pm 1.76^{\#}$ & $3.36 \pm 0.20$ \\
\hline
\end{tabular}

Data are presented as mean \pm SEM (six animals/group)

\# Significant difference between animal groups (normal control EAC control, EAC + 1/5 $\mathrm{LD}_{50}$ A. amoreuxi venom, EAC + cisplatin and $1 / 5 \mathrm{LD}_{50} A$. amoreuxi venom) using one-way ANOVA $(P \leq 0.05)$ followed by a Tukey post hoc test for multiple comparisons

Table 3 Effect of $A$. amoreuxi venom on biochemical parameters in serum and liver of EAC-bearing mice

\begin{tabular}{lcrrrrr}
\hline & \multicolumn{1}{l}{ AST } & \multicolumn{1}{c}{ ALP } & Creatinine & \multicolumn{1}{l}{ GSH } & MDA & PCC \\
\hline Normal control & $68.27 \pm 0.91$ & $82.74 \pm 1.52$ & $0.81 \pm 0.07$ & $711.07 \pm 2.20$ & $37.80 \pm 0.40$ & $2.26 \pm 0.43$ \\
EAC control & $123.82 \pm 1.10$ & $165.30 \pm 1.14$ & $1.58 \pm 0.11$ & $668.94 \pm 1.51$ & $45.47 \pm 1.28$ & $5.16 \pm 0.74$ \\
EAC + 1/5 LD 50 A. amoreuxi venom & $85.08 \pm 0.79$ & $90.02 \pm 1.30$ & $1.54 \pm 0.05$ & $729.90 \pm 1.10$ & $32.48 \pm 0.41$ & $4.23 \pm 0.61$ \\
EAC + cisplatin (0.25 mg/kg) & $69.34 \pm 0.86$ & $99.20 \pm 1.73$ & $1.47 \pm 0.03$ & $750.98 \pm 0.94$ & $35.24 \pm 1.01$ & $4.90 \pm 0.66$ \\
$1 / 5$ LD $_{50}$ A. amoreuxi venom & $77.13 \pm 1.58^{\#}$ & $135.71 \pm 1.02^{\#}$ & $1.51 \pm 0.02^{\#}$ & $702.00 \pm 7.89^{\#}$ & $35.08 \pm 4.06^{\#}$ & $3.99 \pm 0.24^{\#}$ \\
\hline
\end{tabular}

Data are presented as mean \pm SEM (six animals/group)

\# Significant difference between animal groups (normal control EAC control, EAC + 1/5 $\mathrm{LD}_{50}$ A. amoreuxi venom, EAC + cisplatin and 1/5 LD ${ }_{50}$ A. amoreuxi venom) using one-way ANOVA $(P \leq 0.05)$ followed by a Tukey post hoc test for multiple comparisons 

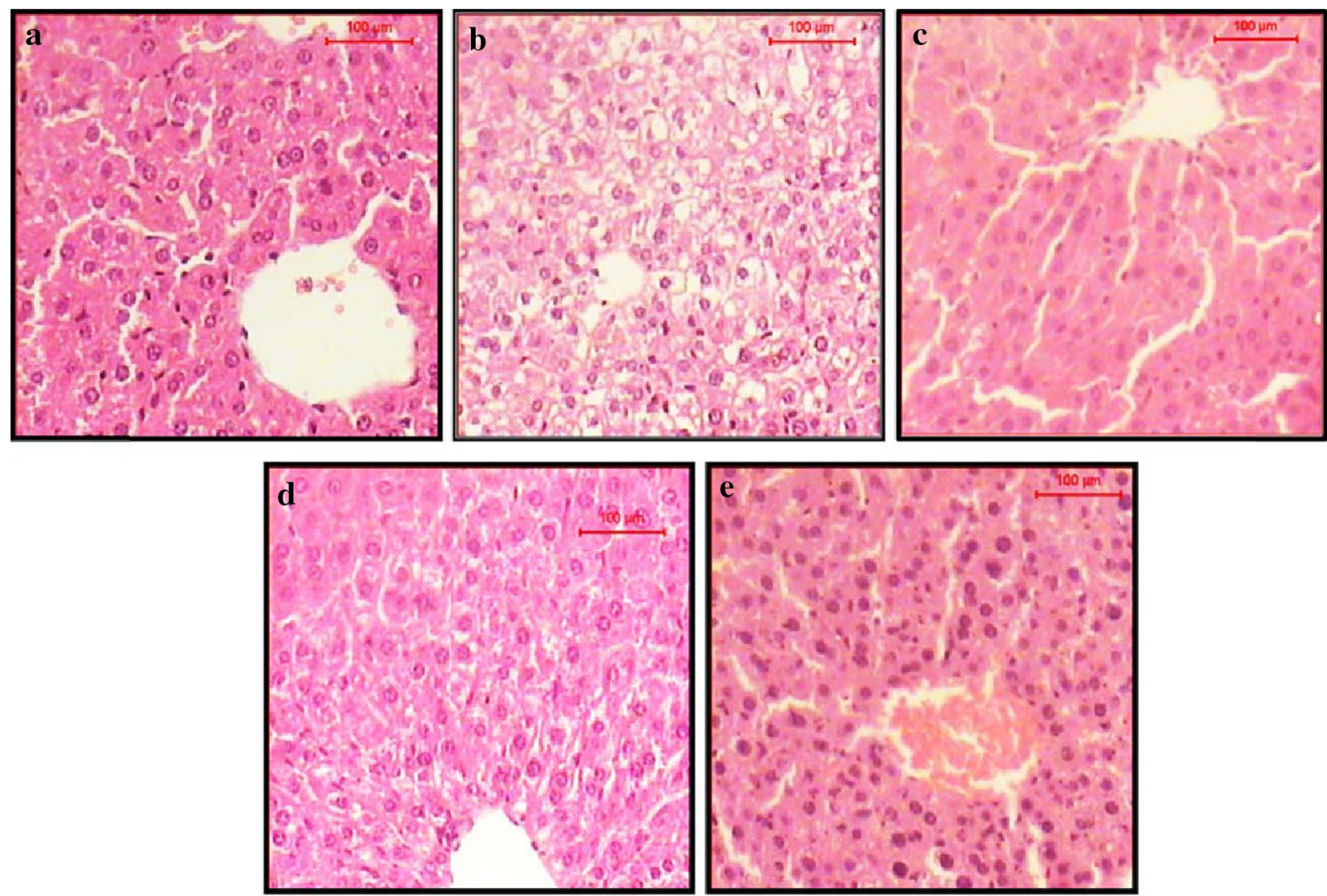

Fig. 3 TS of liver of a normal control mice shows the normal architecture of hepatic lobule. The central vein surrounded by cords of hepatocytes. Between the strands of hepatocytes the narrow blood sinusoids are often seen, $\mathbf{b}$ EAC control mice shows hydropic degeneration of the hepatocytes, loss of cell boundaries and ballooning degeneration. Some other hepatocytes showed nuclear pyknosis and karyolysis, c $1 / 5 \mathrm{LD}_{50}$ of venomtreated EAC-bearing mice shows the hepatic lobule that appear more or less like normal, $\mathbf{d}$ cisplatin-treated EAC-bearing mice shows the hepatic lobule that appear more or less like normal, some hepatocytes shows hydropic degeneration and ballooning degeneration, e $1 / 5 L_{50}$ of venom, shows the hepatic lobule that appear more or less like normal. Notice the enlargement and hyperchromasia in the nuclei of the hepatocytes (H\&E, scale bar $100 \mu \mathrm{m}$, magnification $\times 400)$

various necrotic and apoptotic manifestations following treatment with scorpion venoms on different cancer cell lines such as massive releasing of $\mathrm{LDH}$, up-regulation of caspase- 3 activity, membrane blebbing, chromatin condensation and DNA degradation (Li et al. 1997; Gupta et al. 2007; Gomes et al. 2010; Zargan et al. 2011a, b, c). In this regard, our finding (DNA fragmentation in treated cells) may give an indication about the apoptotic potency of $A$. amoreuxi venom on MCF-7 cells. Interestingly, these results were further supported by enhanced expression of caspase-3 in Ehrlich solid tumor tissues following scorpion venom treatment.

Ascites fluid constitutes an essential nutritional source for tumor cells growing and development (Gupta et al. 2004). Our data showed that IP administration of $A$. amoreuxi venom significantly reduced the ascites (tumor volume), tumor cell count, and increased the percentage of trypan blue positive stained dead cells in tumor-bearing mice. The reduction in tumor volume could be attributed to the treatment of $A$. amoreuxi venom (1) inhibited the proliferation of EAT cells; (2) enhanced apoptotic pathways of cancer cells and (3) direct necrotizing effect of scorpion venom phospholipase A2/cytolytic peptides (Almaaytah et al. 2012). Consequently, A. amoreuxi venom treatment significantly increased MST and \%ILS as compared to EAC control group. Life span prolongation $(>25 \%)$ is directly related to the decrease in viable cell count and ascitic fluid accumulation. It is well known that prolongation of life span is one of the important criteria to evaluate potency of anticancer drugs. According to the criteria of National Cancer Institute, T/C exceeding $125 \%$ and ILS exceeding $25 \%$ indicate that the drug has a significant anti-tumor activity (Plowman et al. 1997; Gupta et al. 2004; Agrawal et al. 2011). 


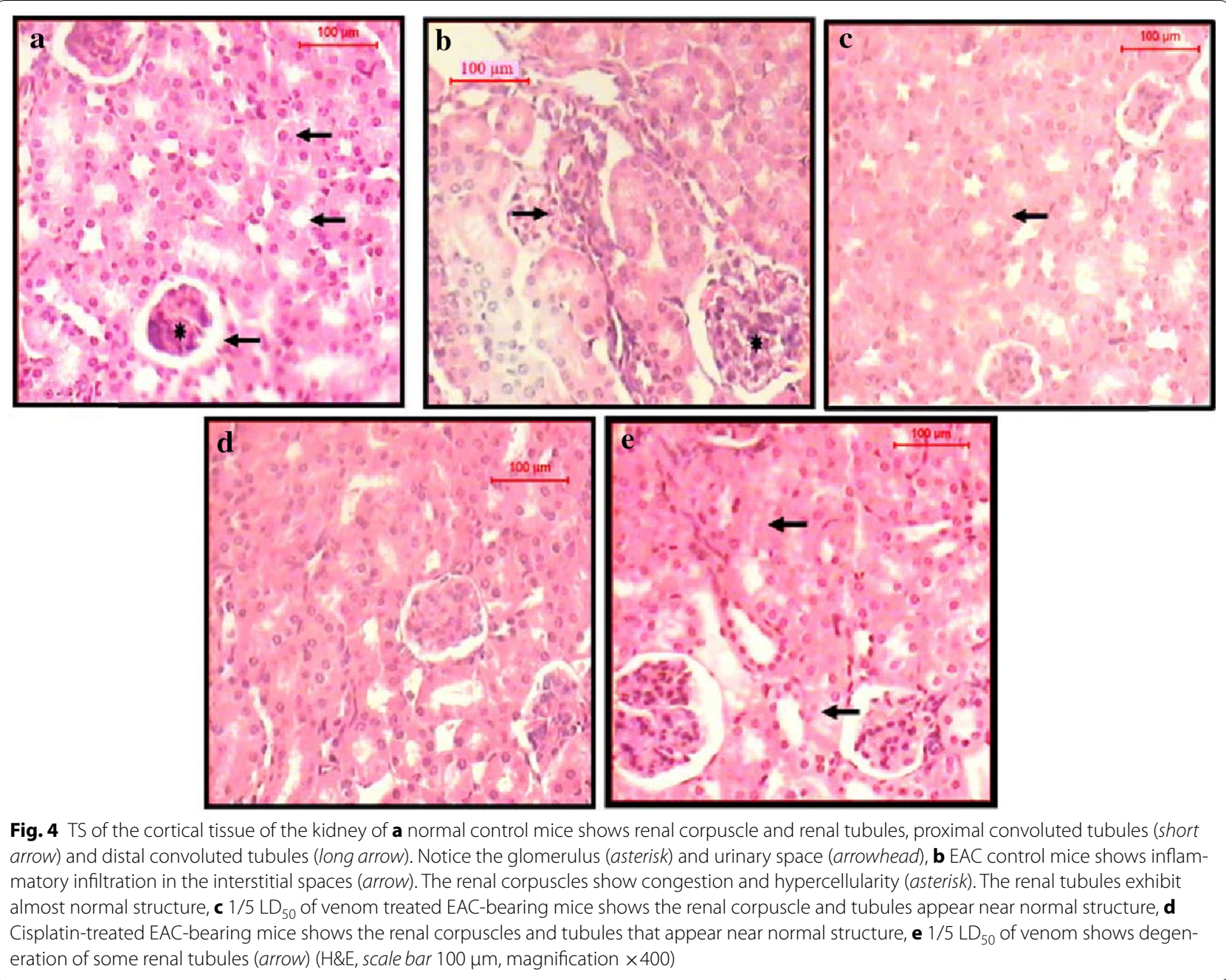

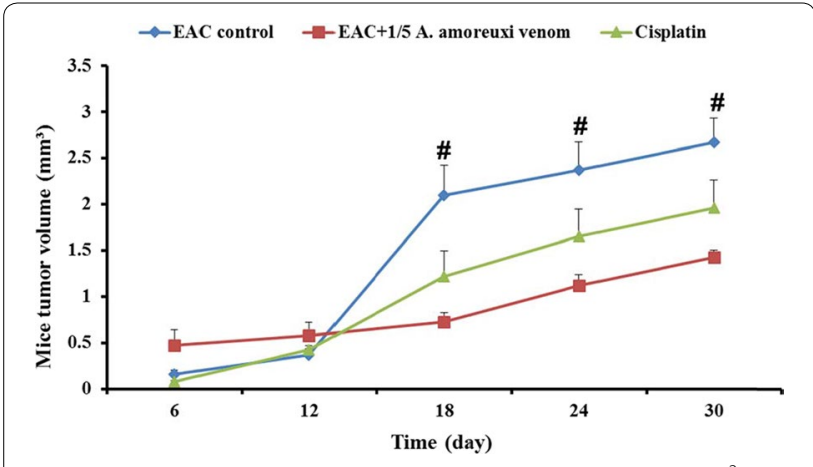

Fig. 5 Effect of A. amoreuxi venom on solid tumor volume $\left(\mathrm{mm}^{3}\right)$ of EAC-bearing mice. Data are presented as mean \pm SEM (five animals/ group). Hash symbol represents a significant difference between the three animal groups (EAC control, EAC $+1 / 5 \mathrm{LD}_{50} A$. amoreuxi venom and $E A C+$ cisplatin) at different time intervals $(6,12,18,24$ and 30 days) using one-way ANOVA ( $P \leq 0.05$ ) followed by a Tukey post hoc test for multiple comparisons
Myelosuppression and anemia (reduced hemoglobin) have been frequently observed in ascites carcinoma (Maseki et al. 1981). Anemia encountered in ascites carcinoma is mainly due to iron deficiency, either by hemolytic or myelopathic conditions, which finally lead to reduced RBCs' count (Sreelatha et al. 2011). In the present study, elevated WBCs' count, reduced hemoglobin and RBCs' count were observed in EAC control mice, where administration of $A$. amoreuxi venom restored hemoglobin level and maintained normal values of RBCs and WBCs. The result of total differential leucocytes count revealed that neutrophils increased within EAC-bearing mice might be due to the acute inflammatory response or stress due to proliferation of EAT cells (Hashem et al. 2004). While neutrophils present in EAC-bearing mice treated with $A$. amoreuxi venom might be decreased as a result of immunostimulating effect of scorpion venom and defence of the host against 

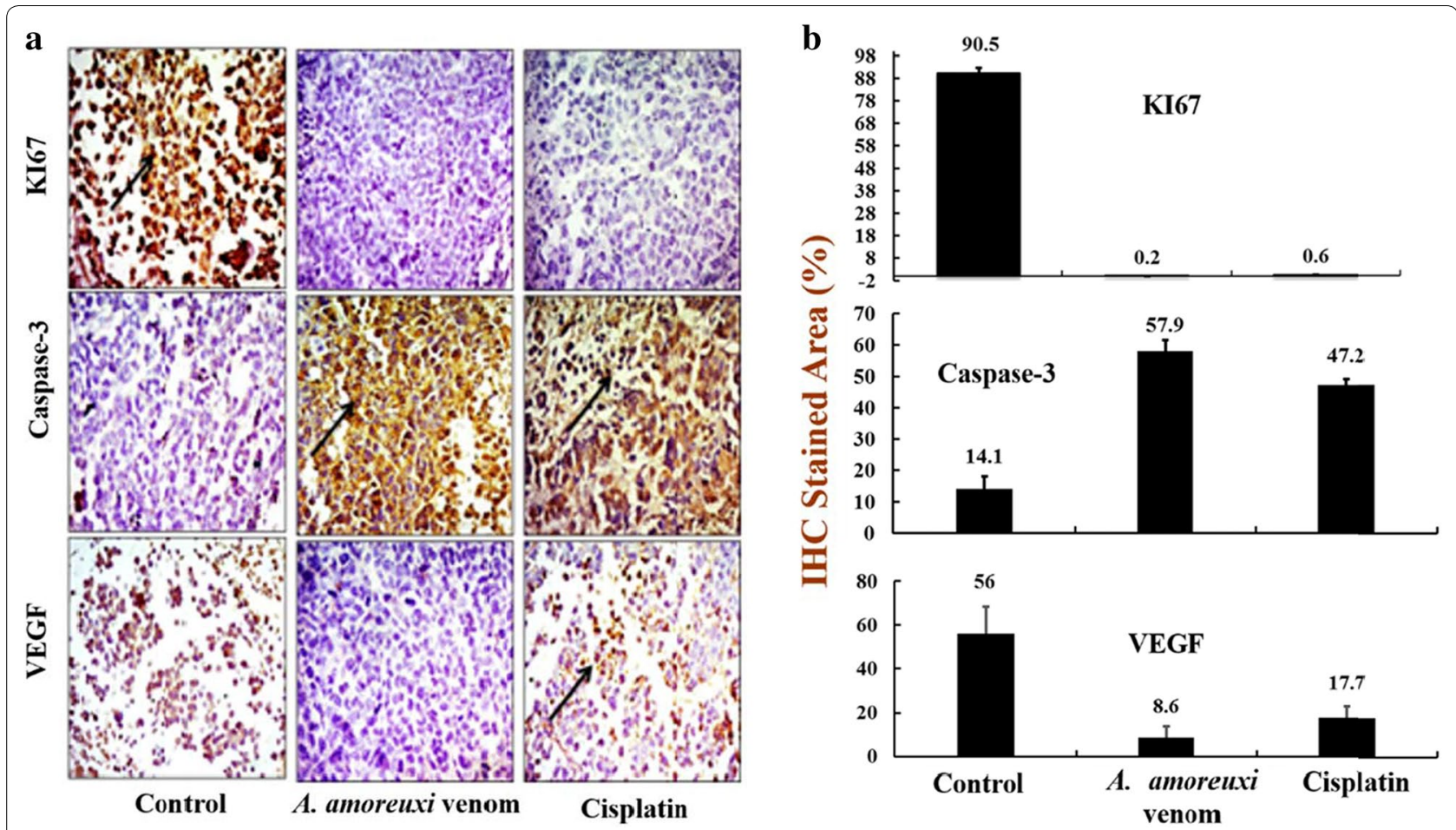

Fig. 6 a Immunohistochemistry of KI67, caspase-3 and VEGF in tumor sections. Tumorized mice were treated with A. amoreuxi venom (1/5 LD 50$)$ and cisplatin every other day for 30 days then sacrificed and solid tumor was excised to processed for $\mathrm{HC}$ studies. Randomly selected areas from each tumor were analyzed. Arrowheads indicate immunohistochemical staining of KI67, caspase-3 and VEGF (magnification: $\times 400$ ). b Comparison between the stained areas of the three tumor markers KI67, caspase-3 and VEGF using Image J

tumor cells. The reversal of hematological parameters indicates that this venom may possess protective action on the hematopoietic system without inducing myelotoxicity. For 14 days, $A$. amoreuxi venom did not exhibit any adverse effect (Sreelatha et al. 2011). Regarding the elevated liver enzymes (ALP and AST) in EAC-bearing mice, lack of hepatic toxicity was observed upon treatment with $A$. amoreuxi venom, indicating that the venom has a protective effect against organ dysfunction and cellular injury of liver. These results were further supported by liver histopathology. Recently, Bekkari and LarabaDjebari (2015) reported the beneficial effects of A. australis venom which partially restored the hepatic alteration induced by the carcinogenic agent of fumonisin (FB1 mycotoxin). Moreover, reducing extent of oxidative stress may explain how $A$. amoreuxi venom protected liver of treated animals from damage induced by tumor. We propose that treatment with $A$. amoreuxi venom decreased the tumor burden and consequently decrease oxidative stress manifested by restoring levels of MDA, PCC and GSH in liver cells. It was reported that reactive oxygen species (ROS) are probable mediators of cytotoxicity and their role in cancer development, metastasis, progression, and survival is well documented (Cerutti 1994; Sur and Ganguly 1994; Iqbal and Okada 2003; Goswami et al. 2008; Tong et al. 2015). Interestingly, similar results were obtained with the venom of $A$. australis which significantly decreased level of oxidative stress biomarkers in mice hepatic tumor (Bekkari and Laraba-Djebari 2015).

The present results also showed that the tumor weights and volumes of Ehrlich solid tumor were significantly decreased in mice-treated with $A$. amoreuxi venom according to our morphometrical and histological data. Some sort of shrinkage of tumors occurred, and the delay of tumor growth was evident. Inhibition of solid tumor growth by this venom might be as a consequence of cell cycle arrest, apoptosis and/or necrosis of tumor cells or it was the result of activation of immune system by scorpion venom. Inhibition of cell proliferation is considered as a basic parameter in cancer studies (Van Heusden et al. 1997). Uncontrolled cell cycle progression has been considered as a sign of cancer development, and therefore, is a usual target for developing potential anti-cancer drugs (Deep and Agarwal 2008). In this communication, the proliferation index was investigated through evaluating the expression of Ki67 in solid tumors of control and venom-treated mice. The data clearly indicated that $A$. amoreuxi venom inhibited expression of Ki67 in 
tumor tissues as compared to control animals. Ki-67 is a nuclear protein expressed in proliferating cells (in all phases of the cell cycle except G0) and serves as a good marker for proliferation and may be required for maintaining cell proliferation (Schluter et al. 1993; Miller et al. 1994). Venoms from various scorpions have been reported to prevent propagation of different cell lines such as prostate cancer, human leukemia and neuroblastoma (Gupta et al. 2007; Zhang et al. 2009; Zargan et al. 2011a). For example, venom of $A$. crassicauda inhibited proliferation of human neuroblastoma cell lines through arresting S-phase and induction of apoptosis (Zargan et al. 2011a). Apoptosis is an important pathway in antitumor drug response (Makin and Dive 2001; Galeano et al. 2005). Two pathways have been described for cells undergoing apoptosis; (1) death-receptor-induced apoptosis (extrinsic pathway through activation caspases-8, 10 and (2) mitochondria-mediated apoptosis (intrinsic pathway through activation of caspases-9) ( $\mathrm{Hu}$ and Kavanagh 2003; Franco et al. 2009). Caspase-3 is a key protease necessary for the execution of apoptosis via the activation of caspases-8 leading to DNA damage and cell death (Zargan et al. 2011a). The venom of $A$. amoreuxi enhanced expression of caspase- 3 in solid tumor tissues as compared to their control group. This finding was concomitant with our in vitro study and may explain mechanism of DNA fragmentation in MCF-7 cells treated with $A$. amoreuxi venom. Furthermore, A. amoreuxi venom revealed anti-angiogenic activity through down-regulation the expression of VEGF in solid tumor. Inhibition of VEGF in tumor is an attractive strategy used to impact angiogenesis-dependent tumor growth and metastasis. Increased VEGF expression is closely associated with an increase in microvessel density (Sadick et al. 2005). Indeed, there are few studies reported capability of scorpion venom peptides to suppress neovascularization and angiogenesis in tumor tissues through decreasing the level of angiogenic factors such as VIII, alpha-SMA, Dll4, Notch1 and VEGF (Lima e Silva et al. 2010; Sun et al. 2011).

\section{Concluding remarks}

Androctonus amoreuxi venom exerted cytotoxic effects on tumor cells via anti-proliferative, apoptotic and antiangiogenic activities. Using recent technologies of venomics (venom proteomics and transcriptomics), further studies are needed towards characterization of the active components from this venom (and other scorpion species inhabiting the Egyptian deserts) and developing them into potential anticancer agents. Moreover, the present study opens the door for detailed investigations about interaction of scorpion venom and conventional antitumor drugs such as cisplatin and others.

\section{Authors' contributions}

MAA designed and supervised the entire study, participated in analyzing the data and wrote the manuscript. WKT, MMA carried out biochemical experiments and participated in analyzing the data. NMS revised the manuscript. MLS revised the manuscript and participated in the interpretation of data. All authors read, approved the final manuscript.

\section{Author details}

${ }^{1}$ Zoology Department, Faculty of Science, Tanta University, Tanta, Egypt. ${ }^{2}$ Zoology Department, Faculty of Science, Suez University, Suez, Egypt. ${ }^{3}$ Pharmacology Department, Faculty of Veterinary Medicine, Suez Canal University, Ismailia 41522, Egypt. ${ }^{4}$ Zoology Department, Faculty of Science, Suez Canal University, Ismailia 41522, Egypt.

\section{Competing interests}

The authors declare they have no competing interests.

Received: 4 November 2015 Accepted: 3 May 2016

Published online: 10 May 2016

\section{References}

Abdel-Rahman MA, Quintero-Hernandez V, Possani LD (2013) Venom proteomic and venomous glands transcriptomic analysis of the Egyptian scorpion Scorpio maurus palmatus (Arachnida: Scorpionidae). Toxicon 74:193-207

Abdel-Rahman MA, Harrison PL, Strong PN (2015) Snapshots of scorpion venomics. J Arid Environ 112:170-176

Abdel-Rahman MA, Quintero-Hernandez V, Possani LD (2016) Scorpion venom gland transcriptomics and proteomics: an overview. In: Gopalakrishnakone P (ed) Toxinology. Venom genomics and proteomics. Springer, Berlin

Agrawal SS, Saraswati S, Mathur R, Pandey M (2011) Cytotoxic and antitumor effects of brucine on Ehrlich ascites tumor and human cancer cell line. Life Sci 89:147-158

Al-Asmari AK, Islam M, Al-Zahrani AM (2016) In vitro analysis of the anticancer properties of scorpion venom in colorectal and breast cancer cell lines. Oncol Lett 2:1256-1262

Almaaytah A, Albalas Q (2014) Scorpion venom peptides with no disulfide bridges: a review. Peptides 51:35-45

Almaaytah A, Zhou M, Wang L, Chen T, Walker B, Shaw C (2012) Antimicrobial/ cytolytic peptides from the venom of the North African scorpion, Androctonus amoreuxi: biochemical and functional characterization of natural peptides and a single site-substituted analog. Peptides 35:291-299

Bancroft JP, Stevens A, Turner DR (1996) Theory and practice of histopathological techniques, 4th edn. Churchill Living stone, New York

Bekkari N, Laraba-Djebari F (2015) Beneficial effects of Androctonus australis hector venom and its non-toxic fraction in the restoration of early hepatocyte-carcinogenesis induced by FB1 mycotoxin: involvement of oxidative biomarkers. Exp Mol Pathol 99:198-206

Beutler E, Doron O, Kelly B (1963) Improved method for the determination of blood glutathione. J Lab Clin Med 61(5):882-888

Bincoletto C, Eberlin S, Figueredo CA, Luengo MB, Queiroz ML (2005) Effects produced by Royal Jelly on haematopoiesis: relation with host resistance against Ehrlich ascites tumour challenge. Int Immunopharmacol 5(4):679-688

Bloch M, Ousingsawat J, Simon R, Schraml P, Gasser TC, Mihatsch MJ, Kunzelmann K, Bubendorf L (2007) KCNMA1 gene amplification promotestumor cell proliferation in human prostate cancer. Oncogene 26:2525-2534

Caliskan F, Ergene E, Sogut I, Hatipoglu I, Basalp A, Sivas H, Kanbak G (2013) Biological assays on the effects of Acra3 peptide from Turkish scorpion Androctonus crassicauda venom on a mouse brain tumor cell line $(\mathrm{BC} 3 \mathrm{H} 1)$ and production of specific monoclonal antibodies. Toxicon 76:350-361

Cerutti PA (1994) Oxy-radicals and cancer. Lancet 344:862-863

Deep G, Agarwal R (2008) New combination therapies with cell cycle agents. Curr Opin Investig Drugs 9:591-604

Deshane J, Garner CC, Sontheimer H (2003) Chlorotoxin inhibits glioma invasion via matrix metalloproteinase-2. J Biol Chem 278:4135-4144 
Ding J, Chua PJ, Bay BH, Gopalakrishnakone P (2014) Scorpion venoms as a potential source of novel cancer therapeutic compounds. Exp Biol Med 239(4):387-393

Ferlay J, Soerjomataram I, Ervik M, Dikshit R, Eser S, Mathers C, Rebelo M, Parkin DM, Forman D, Bray F (2013) GLOBOCAN 2012 v1.0, cancer incidence and mortality worldwide: IARC cancer base no. 11 [Internet]. Lyon, France. International Agency for Research on Cancer

Franco R, Sanchez-Olea R, Reyes-Reyes EM, Panayiotidis MI (2009) Environmental toxicity, oxidative stress and apoptosis: Ménage à Trois. Mutat Res $674: 3-22$

Frankenberg $L$ (1979) Cardiac puncture in the mouse through the anterior thoracic aperture. Lab Anim 13(4):311-312

Galeano E, Nieto E, García-Pérez Al, Delgado MD, Pinilla M, Sancho P (2005) Effects of the antitumoural dequalinium on NB4 and K562 human leukemia cell lines. Mitochondrial implication in cell death. Leuk Res 29:1201-1211

Giri K, Ghosh U, Bhattacharyya NP, Basak S (2003) Caspase 8 mediated apoptotic cell death induced by beta-sheet forming polyalanine peptides. FEBS Lett 555:380-384

Gomes A, Bhattacharjee P, Mishra R, Biswas AK, Dasgupta SC, Giri B (2010) Anticancer potential of animal venoms and toxins. Indian J Exp Biol 48:93-103

Goswami B, Rajappa M, Sharma M, Sharma A (2008) Inflammation: its role and interplay in the development of cancer, with special focus on gynecological malignancies. Int J Gynecol Cancer 18:591-599

Gupta A, Mazumder UK, Kumar RS, Kumar TS (2004) Anti-tumor activity and antioxident role of Bauhinia racemosa against Ehrlich ascites carcinoma in Swiss albino mice. Acta Pharmacol Sin 25(8):1070-1076

Gupta SD, Debnath A, Saha A, Giri B, Tripathi G, Vedasiromoni JR, Gomes An, Gomes Ap (2007) Indian black scorpion (Heterometrus bengalensis Koch) venom induced antiproliferative and apoptogenic activity against human leukemic cell lines U937 and K562. Leuk Res 31:817-825

Gupta SD, Gomes An, Debnath A, Saha A, Gomes Ap (2010) Apoptosis induction in human leukemic cells by a novel protein Bengalin, isolated from Indian black scorpion venom: through mitochondrial pathway and inhibition of heat shock proteins. Chem Biol Interact 183:293-303

Harrison PL, Abdel-Rahman MA, Miller K, Strong PN (2014) Antimicrobial peptides from scorpion venoms. Toxicon 88C:115-137

Harrison PL, Abdel-Rahman MA, Strong PN, Tawfik MM, Miller K (2016) Characterisation of three alpha-helical antimicrobial peptides from the venom of Scorpio maurus palmatus. Toxicon 117:30-36

Hashem MA, Mohammed HM, Magda SH (2004) Clinicopathological, pathological and biophysical studies on the effect of electromagnetic field on the Ehrlich tumor cells implanted in mice. Egypt J Comp Clin Pathol 17(2):117-147

Hu W, Kavanagh JJ (2003) Anticancer therapy targeting the apoptotic pathway. Oncology 4:721-729

lqbal M, Okada S (2003) Induction of NAD(P)H: quinone reductase by probucol: a possible mechanism for protection against chemical carcinogenesis and toxicity. Pharmacol Toxicol 93:259-263

Jager H, Dreker T, Buck A, Giehl K, Gress T, Grissmer S (2004) Blockage of intermediate-conductance $\mathrm{Ca}^{2+}$ activated $\mathrm{K}^{+}$channels inhibit human pancreatic cancer cell growth in vitro. Mol Pharmacol 65:630-638

Jakob C, Liersch T, Meyer W, Becker H, Baretton GB, Aust DE (2008) Predictive value of Ki67 and p53 in locally advanced rectal cancer: correlation with thymidylate synthase and histopathological tumor regression after neoadjuvant 5-FU-based chemoradiotherapy. World J Gastroentero 14:1060-1066

Jang SH, Choi SY, Ryu PD, Lee SY (2011) Anti-proliferative effect of Kv1.3 blockers in A549 human lung adenocarcinoma in vitro and in vivo. Eur J Pharmacol 651:26-32

Jemal A, Bray F, Center MM, Ferlay J, Ward E, Forman D (2011) Global cancer statistics. CA Cancer J Clin 61:69-90

Levine RL, Williams JA, Stadtman ER, Shacter E (1994) Carbonyl assays for determination of oxidatively modified proteins. Methods Enzymol 233:346-357

Li J, Yen C, Liaw D, Podsypanina K, Bose S, Wang SI, Puc J, Miliaresis C, Rodgers L, McCombie R, Bigner SH, Giovanella BC, Ittmann M, Tycko B, Hibshoosh H, Wigler MH, Parsons R (1997) PTEN, a putative protein tyrosine phosphatase gene mutated in human brain, breast, and prostate cancer. Science 275(5308):1943-1947
Lima e Silva R, Shen J, Gong YY, Seidel CP, Hackett SF, Kesavan K, Jacoby DB, Campochiaro PA (2010) Agents that bind annexin A2 suppress ocular neovascularization. J Cell Physiol 225(3):855-864

Liu YF, Zhang ZG, Mao YZ, Cui Y, Hu N, Wang Y (2009) Production and antitumor efficacy of recombinant Buthus martensii Karsch AGAP. Asian J Tradit Med 4:228-233

Makin G, Dive C (2001) Apoptosis and cancer chemotherapy. Trends Cell Biol 11(11):S22-S26

Mamelak AN (2011) Targeted antitumor therapy with the scorpion venom chlorotoxin. Drugs Future 36:615-625

Maseki M, Nishiagaki I, Hagishara M, Tamoda Y, Yagi K (1981) Lipid peroxidation levels and lipid content of serum lipoprotein fractions of pregnant subjects with or without preeclampsia. Clin Chim Acta 41:424-426

Meier J, Theakston RDG (1986) Approximate LD50, determinations of snake venoms using eight to ten experimental animals. Toxicon 24(4):395-401

Miller TP, Grogan TM, Dahlberg S, Spier CM, Braziel RM, Banks PM, Foucar K, Kjeldsberg CR, Levy N, Nathwani BN (1994) Prognostic significance of the Ki-67 associated proliferative antigen in aggressive non-Hodgkin's lymphomas. A prospective South west oncology group trial. Blood 83:1460-1466

Mohamed MM, Mohamed MA, Fikry NM (2003) Enhancement of antitumor effects of 5-fluorouracil combined with ultrasound on Ehrlich ascites tumor in vivo. Ultrasound Med Biol 29:1635-1643

Nicol BM, Prasad SB (2006) The effects of cyclophosphamide alone and in combination with ascorbic acid against murine ascites Dalton's lymphoma. Indian J Pharmacol 38:260-265

Ohkawa HW, Ohishi N, Yagi K (1979) Assay for lipid peroxides in animal tissues by thiobarbituric acid reaction. Anal Biochem 95:351-358

Omran MAA (2003) In vitro anticancer effect of scorpion Leiurus quinquestriatus and Egyptian cobra venom on human breast and prostate cancer cell lines. J Med Sci 3:66-86

Orsolic N, Tadic Z, Benkovic V, Horvat A, Lisicic D, Basic I (2006) Stimulation of hematopoiesis by a water-soluble derivative of propolis in mice. Pharmacologyonline 3:698-705

Ortiz E, Gurrola GB, Schwartz EF, Possani LD (2015) Scorpion venom components as potential candidates for drug development. Toxicon 93:125-135

Peitsch MC, Muller C, Tschopp J (1993) DNA fragmentation during apoptosis is caused by frequent single-strand cuts. Nucleic Acids Res 21:4206-4209

Plowman J, Dykes DJ, Hollingshead M, Simpson-Herren L, Alley MC (1997) Human tumor xenograft models in $\mathrm{NCl}$ drug development. In: Teicher B, Totowa, NJ (eds) Anticancer drug development guide: preclinical screening, clinical trials and approval. Humana Press, pp 101-125

Rodriguez de la Vega RC, Possani LD (2005) Overview of scorpion toxins specific for $\mathrm{Na}+$ channels and related peptides: biodiversity, structure-function relationships and evolution. Toxicon 46:831-844

Sadick H, Naim R, Gossler U, Hormann K, Riedel F (2005) Angiogenesis in hereditary hemorrhagic telangiectasia: VEGF165 plasma concentration in correlation to the VEGF expression and microvessel density. Int J Mol Med 15:15-19

Santos FM, Latorre AO, Hueza IM, Sanches DS, Lippi LL, Gardner DR, Spinosa HS (2011) Increased antitumor efficacy by the combined administration of swainsonine and cisplatin in vivo. Phytomedicine 18:1096-1101

Schluter C, Duchrow M, Wohlenberg C, Becker MHG, Key G, Flad HD, Gerdes $J$ (1993) The cell proliferation-associated antigen of antibody Ki-67: a very large, ubiquitus nuclear protein with numerous repeated elements, representing a new kind of cell cycle-maintaining proteins. J Cell Biol 123:513-522

Shao JH, Kang N, Liu YF, Song YB, Wu CF, Zhang JH (2007) Purification and characterization of an analgesic peptide from Buthus martensii Karsch. Biomed Chromatogr 21:1266-1271

Shao JH, Cuia Yong, Zhao MY, Wub CF, Liub YF, Zhang JH (2014) Purification, characterization, and bioactivity of a new analgesic-antitumor peptide from Chinese scorpion Buthus martensii Karsch. Peptides 53:89-96

Skehan P, Storeng R, Scudiero D, Monks A, McMahon J, Vistica D, Warren JT, Bokesch H, Kenney S, Boyd MR (1990) New colorimetric cytotoxicity assay for anticancer-drug screening. J Natl Cancer Inst 82:1107-1112

Song YM, Tang XX, Chen XG, Gao BB, Gao E, Bai L (2005) Effects of scorpion venom bioactive polypeptides on platelet aggregation and thrombosis and plasma 6-keto-PG F1 and TXB2 in rabbits and rats. Toxicon 46:230-235 
Sreelatha S, Padma PR, Umasankari E (2011) Evaluation of anticancer activity of ethanol extract of Sesbania grandiflora (Agati Sesban) against Ehrlich ascites carcinoma in Swiss albino mice. J Ethnopharmacol 134:984-987

Sun X, Zhang Y, Jia Q, Wang Z, Wang Z, Zhang W (2011) Effect of polypeptide extract from scorpion venom (PESV) with chemotherapy inhibited angiogenesis of Lewis lung carcinomas. Zhongguo Zhong Yao Za Zhi 36(12):1644-1649

Sur P, Ganguly DK (1994) Tea plant roots extract (TRE) as an antineoplastic agent. Planta Med 60:106-109

Tong L, Chuang CC, Wu S, Zuo L (2015) Reactive oxygen species in redox cancer therapy. Cancer Lett 367(1):18-25

Van Heusden J, de Jong P, Ramaekers F, Bruwiere H, Borgers M, Smets G (1997) Fluorescein-labeled tyramide strongly enhances the detection of low bromodeoxyuridine incorporation levels. J Histochem Cytochem 45:315-319

Wang CG, He XL, Shao F, Liu W, Ling MH, Wang DC (2001) Molecular characterization of an anti-epilepsy peptide from the scorpion Buthus martensii Karsch. Eur J Biochem 268:2480-2485

Yu JK, Zhang JH, Wang QZ, Liu CM (1992) Effect of AEP obtained from the venom of Buthus martensii Karsch and its comparison with other similar drugs. J Shenyang Coll Pharm 9:200-204
Zargan J, Sajad M, Umar S, Naime M, Ali S, Khan HA (2011a) Scorpion (Androctonus crassicauda) venom limits growth of transformed cells (SH-SY5Y and MCF-7) by cytotoxicity and cell cycle arrest. Exp Mol Pathol 91:447-454

Zargan J, Sajad M, Umar S, Naime M, Ali S, Khan HA (2011b) Scorpion (Odontobuthus doriae) venom induces apoptosis and inhibits DNA synthesis in human neuroblastoma cells. Mol Cell Biochem 384:173-181

Zargan J, Umar S, Sajad M, Naime M, Ali S, Khan HA (2011c) Scorpion venom (Odontobuthus doriae) induces apoptosis by depolarization of mitochondria and reduces S-phase population in human breast cancer cells (MCF-7). Toxicol In Vitro 25:1748-1756

Zeng XC, Corzo G, Hahin R (2005) Scorpion venom peptides without disulfide bridges. IUBMB Life 57:13-21

Zhang YY, Wu LC, Wang ZP, Wang ZX, Jia Q, Jiang GS, Zhang WD (2009) Antiproliferation effect of polypeptide extracted from scorpion venom on human prostate cancer cells in vitro. J Clin Med Res 1:24-31

Zhao YL, Cai XT, Ye TM, Huo JG, Liu C, Zhang SQ (2011) Analgesic-antitumor peptide inhibits proliferation and migration of SHG-44 human malignant glioma cells. J Cell Biochem 112:2424-2434

\section{Submit your manuscript to a SpringerOpen ${ }^{\circ}$ journal and benefit from:}

- Convenient online submission

- Rigorous peer review

- Immediate publication on acceptance

- Open access: articles freely available online

- High visibility within the field

- Retaining the copyright to your article

Submit your next manuscript at springeropen.com 